\title{
Identification of novel susceptibility genes in ozone-induced inflammation in mice
}

\author{
A.K. Bauer*, E.L. Travis”, S.S. Malhotra\#, E.A. Rondini*, C. Walker", H-Y. Cho", \\ S. Trivedi ${ }^{\mp}$, W. Gladwell ${ }^{\oplus}$, S. Reddy ${ }^{+}$and S.R. Kleeberger
}

ABSTRACT: Ozone $\left(\mathrm{O}_{3}\right)$ remains a prevalent air pollutant and public health concern. Inf2 is a significant quantitative trait locus on murine chromosome 17 that contributes to susceptibility to $\mathrm{O}_{3}$-induced infiltration of polymorphonuclear leukocytes (PMNs) into the lung, but the mechanisms of susceptibility remain unclear. The study objectives were to confirm and restrict Inf2, and to identify and test novel candidate susceptibility gene(s).

Congenic strains of mice that contained overlapping regions of Inf2 and their controls, and mice deficient in either major histocompatibility complex (MHC) class II genes or the Tnf cluster, were exposed to air or $\mathrm{O}_{3}$. Lung inflammation and gene expression were assessed.

Inf2 was restricted from $16.42 \mathrm{Mbp}$ to $0.96 \mathrm{Mbp}$, and bioinformatic analysis identified MHC class II, the Tnf cluster and other genes in this region that contain potentially informative single nucleotide polymorphisms between the susceptible and resistant mice. Furthermore, $\mathrm{O}_{3}$-induced inflammation was significantly reduced in mice deficient in MHC class II genes or the Tnf cluster genes, compared with wild-type controls. Gene expression differences were also observed in MHC class II and Tnf cluster genes.

This integrative genetic analysis of Inf2 led to identification of novel $\mathrm{O}_{3}$ susceptibility genes that may provide important, new therapeutic targets in susceptible individuals.

KEYWORDS: Inflammation, Iymphotoxin $\alpha$, major histocompatibility complex, mouse, susceptibility, tumour necrosis factor

$\mathbf{T}$ he pollutant ozone $\left(\mathrm{O}_{3}\right)$ is a highly toxic principal oxidant found in urban environments throughout industrialised cities worldwide. $\mathrm{O}_{3}$ exposure has been associated with many adverse health effects, such as exacerbation of asthma [1,2]. Identification of susceptibility genes involved in $\mathrm{O}_{3}$-induced pulmonary injury may provide critical information for future risk assessment as well as general international health policies. In 2006, an estimated one-third of US individuals were at an increased risk of adverse effects caused by $\mathrm{O}_{3}$ and 131 million US residents resided in regions that either approached or exceeded the National Ambient Air Quality Standard of $0.08 \mathrm{ppm} \mathrm{O}_{3}$ [3].

Significant intersubject differences in pulmonary function and inflammatory responses to $\mathrm{O}_{3}$ suggest that genetic background contributes to $\mathrm{O}_{3}$ susceptibility in humans and rodents [4-6]. Furthermore, studies in human subjects have suggested that polymorphisms in oxidant defence genes, such as glutathione $S$-transferase
M1, and quinone metabolism genes, such as NADPH quinone oxidoreductase 1 , associate with differential responsiveness to $\mathrm{O}_{3}[7,8]$. Activating polymorphisms in inflammatory genes, such as tumour necrosis factor alpha (TNF), also enhance susceptibility to $\mathrm{O}_{3}$ and asthma [9]. A genome-wide linkage analysis of $\mathrm{O}_{3}$-induced influx of polymorphonuclear leukocytes (PMNs) in an intercross cohort $\left(\mathrm{B}_{6} \mathrm{C} 3 \mathrm{~F}_{2}\right)$ derived from susceptible C57BL/6 (B6) and resistant $\mathrm{C} 3 \mathrm{H} / \mathrm{HeJ}(\mathrm{C} 3)$ progenitor mouse strains identified a significant susceptibility quantitative trait locus (QTL) on chromosome 17 (inflammation 2; Inf2) [5]. Inf2 (33.73-50.15 Mbp; D17Mit16D17Mit10) contains the $\mathrm{H}-2$ locus, including major histocompatibility complex (MHC) genes and non-MHC genes, such as the pro-inflammatory cytokine Tnf. Pre-treatment of B6 mice with a monoclonal antibody to TNF- $\alpha$ and deletion of TNF- $\alpha$ receptors 1 and $2[5,10]$ significantly attenuated the inflammatory response to $\mathrm{O}_{3}$ relative to control mice, supporting the importance of Tnf as a candidate gene in this model.
AFFILIATIONS

*Dept of Pathobiology and

Diagnostic Investigation, Michigan State University, East Lansing, Ml,

\#University of Texas MD Anderson Cancer Center, Houston, TX,

"Laboratory of Respiratory Biology, NIEHS, Research Triangle Park, NC, and

+Johns Hopkins University,

Baltimore, MD, USA.

\section{CORRESPONDENCE}

A.K. Bauer

Dept of Pathobiology and Diagnostic Investigation

Center for Integrative Toxicology B43 Food Safety and Toxicology BIdg Michigan State University

East Lansing

MI 48824

USA

E-mail: akbauer@msu.edu

Received:

Sept 132009

Accepted after revision:

Nov 222009

First published online:

Dec 232009 
However, these studies did not conclusively identify Tnf as the susceptibility gene in $\operatorname{Inf} 2$. In addition, $\operatorname{Inf} 2$ is located in the most gene dense, polymorphic region of the entire mouse genome, thus making single candidate gene identification difficult [11].

In the current study we sought to confirm the importance of $\operatorname{Inf2}$ in $\mathrm{O}_{3}$-induced lung inflammation, to reduce $\operatorname{Inf2}$, and to identify candidate susceptibility genes. Using an integrative genomics approach, we utilised congenic mouse strains to limit Inf2 from $16.42 \mathrm{Mbp}$ to $0.96 \mathrm{Mbp}$, and bioinformatic analysis which identified MHC class II genes and the entire Tnf cluster as candidate susceptibility loci. Functional analyses of these genes confirmed novel roles for modulation of the inflammatory response to $\mathrm{O}_{3}$ exposure.

\section{MATERIALS AND METHODS}

\section{Mouse strains and $\mathrm{O}_{3}$ exposure}

The following male (6-8 week) congenic mice were used: B10.A-H $2^{h 2} /(2 \mathrm{R}) \mathrm{SgSnJ}$ (2R); B10.A-H2 $2^{h 4} /(4 \mathrm{R}) \mathrm{SgDvEg}$ (4R); B10.A-H $2^{i 5} \mathrm{H} 2-\mathrm{T}_{1}{ }^{a} /(5 \mathrm{R}) \mathrm{SgSnJ}$ (5R); and C3.SW-H2b/SnJ $\left(\mathrm{C} 3 \mathrm{H}-\mathrm{H} 2^{b}\right)$. The congenic region and haplotype for each of the strains are shown in table 1 and figure 1 . Control strains for the congenic mice were C57BL/10SnJ (B10), A/WySnJ (A), and $\mathrm{C} 3 \mathrm{H} / \mathrm{HeSnJ}(\mathrm{HeSnJ})$. The location of the congenic region of the $2 R, 4 R$, and $5 R$ mice with respect to the B10 and A/Wy background strains was identified by genotyping (S.S. Malhotra and E.L. Travis; data not shown). $\mathrm{H} 2{ }^{\mathrm{k}}$ haplotypes are $\mathrm{O}_{3}$-resistant and the $\mathrm{H}_{2}{ }^{\mathrm{b}}$ haplotype is $\mathrm{O}_{3}$-susceptible [5]. Additional strains used for the candidate gene studies were B6.129-H2 ${ }^{\mathrm{dlAb} 1-\mathrm{Ea}} / \mathrm{J}$ (H2- ${ }^{\text {dlAbl-Ea; }}$ B6 background strain), B6.129S2- $L t a^{t m 1 D c h} / \mathrm{J}\left(\mathrm{Lta}^{-/-}, \mathrm{B} 6\right.$ background), B6.129P2-Ltb/Tnf/ $\mathrm{Lta}^{\mathrm{tm} 1 \mathrm{D} v \mathrm{k}} / \mathrm{J}$ (Ltb/Tnf/Lta ${ }^{-/-}$mice, B6 background), C57BL/6J (B6) mice, and $\mathrm{C} 3 \mathrm{H} / \mathrm{HeJ}(\mathrm{C} 3)$ mice. $\mathrm{B} 6$ are $\mathrm{O}_{3}$-susceptible and are $\mathrm{H}_{2}{ }^{\mathrm{b}}$, while $\mathrm{C} 3 \mathrm{H} / \mathrm{HeJ}(\mathrm{C} 3)$ mice are $\mathrm{O}_{3}$-resistant and are $\mathrm{H} 2^{\mathrm{k}}$. All mice were purchased from Jackson Laboratory (Bar Harbor, ME, USA). All animal use was conducted in facilities accredited by the Association for the Assessment and Accreditation of Laboratory Animal Care and approved by the National Institute of Environmental Health Sciences Animal Care and Use Committee and follows the Helsinki convention for the use and care of animals. For air and $\mathrm{O}_{3}$ exposures, mice were caged in a humidity- and temperaturecontrolled room and provided water and pelleted openformula rodent diet NIH-07 (Zeigler Brothers, Gardners, PA, USA) ad libitum (see $\mathrm{O}_{3}$ exposure procedures in the online supplementary material).

\section{Bronchoalveolar lavage fluid analysis}

The procedures used for these techniques have been described previously for right lung lavages and inflammatory cell analysis $[5,10,14]$.

\section{Total RNA isolation and real-time quantitative $R T-P C R$}

Mice were sacrificed immediately after air or $\mathrm{O}_{3}$ exposure, and lungs of each animal were snap-frozen in liquid nitrogen. Total RNA isolation, reverse transcription into cDNA and PCR reaction procedures are described in the online supplementary materials.

\section{Statistics}

Data are expressed as group mean \pm SEM. Two-way ANOVA was used to evaluate the effects of exposure (air versus $\mathrm{O}_{3}$ ) and strain (B10, 2R, 4R, 5R, A, HeSnJ, C3H-H2 ${ }^{\mathrm{b}}, \mathrm{H} 2{ }^{\text {dlAbl-Ea- } /- \text {, }}$ H2- ${ }^{\mathrm{dlAbl}-\mathrm{Ea}+/+}, \mathrm{Lta}^{-/-}, \mathrm{Lta}^{+/+}, \mathrm{Lta} / \mathrm{Tnf} / \mathrm{Ltb}^{-/-}, \mathrm{Lta} / \mathrm{Tnf} / \mathrm{Ltb}^{+/+}, \mathrm{B} 6$, C3) on bronchoalveolar lavage (BAL) phenotypes and mRNA expression. The figure legends contain the number of mice used per experiment. Student-Newman-Keuls test was used for a posteriori comparisons of means. All analyses were performed using a commercial statistical analysis package (SigmaStat; Jandel Scientific Software, San Rafael, CA, USA). Statistical significance was accepted at $\mathrm{p}<0.05$.

\section{RESULTS}

\section{Restriction of Inf2}

Responses to $\mathrm{O}_{3}$ in congenic mice

To confirm the significance of $\operatorname{Inf} 2, \mathrm{C} 3 \mathrm{H}-\mathrm{H} 2^{\mathrm{b}}$ mice which contain Inf2 from a susceptible mouse $\left(\mathrm{H}_{2} \mathrm{~b}\right)$ on an $\mathrm{O}_{3}$-resistant

TABLE 1 Nomenclature and characteristics of the congenic and control strains used for investigation

\begin{tabular}{|c|c|c|c|c|}
\hline \multirow[t]{2}{*}{ Strain name } & \multirow[t]{2}{*}{ Abbreviation } & \multicolumn{2}{|c|}{ Congenic region } & \multirow[t]{2}{*}{ H2 haplotype ${ }^{\#}$} \\
\hline & & Mbp & cM & \\
\hline \multicolumn{5}{|l|}{ Congenic strains } \\
\hline B10.A-H2 $2^{h 2} /(2 R) S g S n J$ & $2 \mathrm{R}$ & 33.74-35.34 & $18.20-19.06$ & $\mathrm{H} 2^{\mathrm{h} 2}$ \\
\hline B10.A-H2 $2^{h 4} /(4 \mathrm{R}) \mathrm{SgDvEgJ}$ & $4 \mathrm{R}$ & $29.09-34.38$ & $16.30-18.64$ & $\mathrm{H} 2^{\mathrm{h} 4}$ \\
\hline \multicolumn{5}{|l|}{ Control strains } \\
\hline C57BL/10SnJ" & B10 & & & $\mathrm{H} 2^{\mathrm{b}}$ \\
\hline AWySnJ ${ }^{+}$ & A & & & $\mathrm{H}^{\mathrm{a}}$ \\
\hline $\mathrm{C} 3 \mathrm{H} / \mathrm{HeSnJ} J^{\S}$ & HeSnJ & & & $\mathrm{H} 2^{\mathrm{k}}$ \\
\hline
\end{tabular}

Mbp and $\mathrm{CM}$ were determined using the Mouse Genome Informatics website [12] and genotyped by S.S. Malhotra and E.L. Travis; data not shown. ${ }^{\#}$ : major histocompatibility complex (MHC) H2 haplotypes according to $\mathrm{MHC} \mathrm{H} 2$ Haplotype Appendix 2 [13]; ${ }^{\circ}$ : background strain for $2 \mathrm{R}$, 4R and $5 \mathrm{R}$ mice; ${ }^{+}$: donor strain for $2 \mathrm{R}$, $4 \mathrm{R}$ and $5 \mathrm{R}$ mice; ${ }^{\S}$ : background strain for $\mathrm{C} 3 \mathrm{H}-\mathrm{H} 2^{\mathrm{b}}$ mice. 


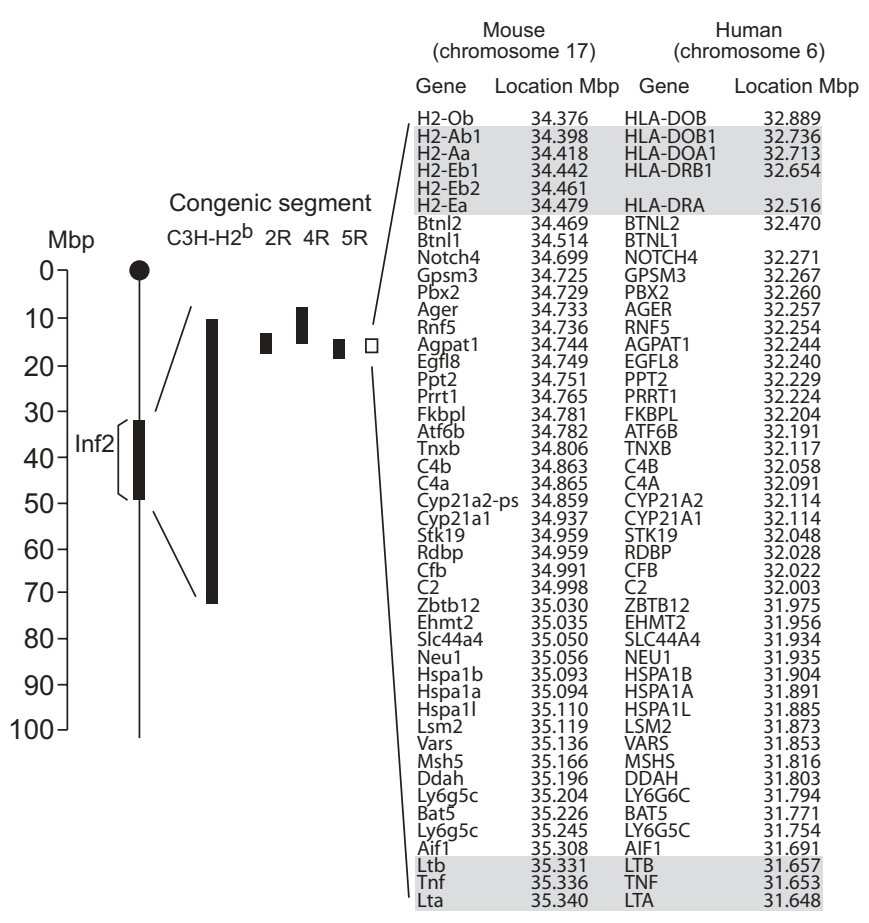

FIGURE 1. Schematic of the chromosome 17 congenic segments for $2 R, 4 R$, $5 \mathrm{R}$ and $\mathrm{C} 3 \mathrm{H}-\mathrm{H} 2^{\mathrm{b}}$ mice that were used to reduce inflammation 2 (Inf2). The congenic segments are shown with respect to Inf2 (on left). The open rectangle represents the reduced Inf2. Mouse genes and human homologues and their chromosomal locations within the reduced Inf2 are shown on the right. While most of the genes are in the same order in both species, some are not. These locations were identified using the Mouse Genome Informatics website [12] and National Centre for Biotechnology Information. The grey shaded genes are major histocompatibility complex (MHC) class II genes and Tnf cluster genes identified as candidate genes using proof of concept experiments (see also figures 5 and 6). Ager: advanced glycosylation end product-specific receptor; Agpat1: 1-acylglycerol-3-phosphate Oacyltransferase 1; Aif1: allograft inflammatory factor 1; Atf6b: activating transcription factor 6 beta; Bat5: HLA-B associated transcript 5; Btn/2: butyrophilin-like 2; Btn/1: butyrophilin-like 1; C2: complement component 2; C4a: complement component 4A; C4b: complement component 4B; Cfb: complement factor B; CREBL1: CAMP responsive element binding protein-like 1; Cyp21a1: cytochrome P450, family 21, subfamily a, polypeptide 1; Cyp21a2-ps: cytochrome P450, family 21, subfamily a, polypeptide 2 pseudogene; Ddah: dimethylarginine dimethylaminohydrolase 2; Egfl8: EGF-like domain 8; Ehmt2: euchromatic histone-lysine N-methyltransferase 2; Fkbpl: FK506 binding protein-like; Gpsm3: G-protein signalling modulator 3; H2Ab1: class II antigen A, beta 1; H2-Aa: class II antigen A, alpha; H2-Eb1: class II antigen E beta; H2-Eb2: class II antigen E beta 2; H2-Ea: class II antigen E alpha; H2-ob: O region beta locus; Hspa1b: heat shock 70 kDa protein 1B; Hspa1a: heat shock $70 \mathrm{kDa}$ protein 1A; Lsm2: LSM2 homolog; Lta: lymphotoxin a; Ltb: lymphotoxin b; Ly6g6c: lymphocyte antigen 6 complex, locus G6C; Ly6g5c: lymphocyte antigen 6 complex, locus G5C; Msh5: mutS homologue 5; Neu1: neuraminidase 1; Notch4: notch gene homologue 4; Pbx2: pre B-cell leukaemia transcription factor 2; Ppt2: palmitoyl-protein thioesterase 2; Prrt1: proline-rich transmembrane protein 1; Psmb8: proteosome subunit, beta type 8; Rdbp: RD RNA-binding protein; Rnf5: ring finger protein 5; S/c44a4: solute carrier family 44, member 4; Stk19: serine/threonine kinase 19; Tap-1: transporter 1, ATP-binding cassette, sub-family B (MDR/TAP); Tap-2: transporter 2, ATP-binding cassette, subfamily B (MDR/TAP); Tnf: tumour necrosis factor; Tnxb: tenascin B; Vars: valyl-tRNA synthetase; Zbtb12: zinc finger and BTB domain containing 12. No human homolog exists for Btnl1.
$\mathrm{H} 2^{\mathrm{K}}$ background (HeSnJ; fig. 1) were exposed to air and $\mathrm{O}_{3}$. Relative to HeSnJ controls, significant increases in mean BAL protein concentration and numbers of macrophages, PMNs and epithelial cells were found in $\mathrm{C} 3 \mathrm{H}-\mathrm{H} 2^{\mathrm{b}}$ mice after 48 and $72 \mathrm{~h}$ exposure to $\mathrm{O}_{3}$ (fig. 2); no strain differences were observed in any parameter in the air-exposed mice. Results thus confirmed the importance of the region of chromosome 17 encompassed by Inf2 in susceptibility to $\mathrm{O}_{3}$-induced inflammation.

To reduce the length of Inf2, $\mathrm{O}_{3}$-induced inflammatory responses in congenic $2 \mathrm{R}, 4 \mathrm{R}$ and $5 \mathrm{R}$ mice were compared with those of similarly exposed $\mathrm{O}_{3}$-susceptible background B10 and $\mathrm{O}_{3}$-resistant donor $\mathrm{A}$ strains. Each congenic strain contains a different region of the Inf2 locus from the A strain mouse on a B10 background (table 1). $\mathrm{O}_{3}$ caused significant increases in mean numbers of macrophages and PMNs in B10 but not A mice compared with respective air-exposed animals, and numbers of macrophages and PMNs were greater in B10 mice compared with $\mathrm{A}$ mice after $\mathrm{O}_{3}$ (fig. 3). The mean numbers of PMNs and macrophages in $2 \mathrm{R}$ and $5 \mathrm{R}$ mice were not different from A strain mice after 48 and $72 \mathrm{~h} \mathrm{O}_{3}$; however, numbers of PMNs and macrophages in $2 \mathrm{R}$ and $5 \mathrm{R}$ mice were significantly lower compared to B10 mice (fig. 3). In contrast, the numbers of BAL fluid (BALF) macrophages and PMNs from $\mathrm{O}_{3}$-exposed $4 \mathrm{R}$ mice were not significantly different from those from $\mathrm{O}_{3^{-}}$ exposed B10 mice, and were greater than those from A, 2R and $5 \mathrm{R}$ mice (fig. 3). The mean BALF protein concentrations were significantly reduced in $2 \mathrm{R}, 4 \mathrm{R}$ and $5 \mathrm{R}$ mice compared to $\mathrm{B} 10$ mice and significantly greater than A mice after 48 and $72 \mathrm{~h} \mathrm{O}_{3}$. Comparison of the mean numbers of macrophages and PMNs between congenic strains with respective congenic regions thus suggested that the 34.38-35.34 Mbp (18.64-19.06 cM) region of chromosome 17 accounted for a major portion of the inflammatory response to $\mathrm{O}_{3}$ in these mice (fig. 1). No differences in mean numbers of BALF epithelial cells were found between the congenic, A or B10 strains after exposure to $\mathrm{O}_{3}$ (fig. 3c).

\section{Candidate gene analysis}

\section{Database search for polymorphisms}

Genes within the reduced region of Inf2 (34.38-35.34 Mbp) were searched for known exon (non-synonymous), intron (including splice sites) and untranslated region (UTR) polymorphisms using the public Mouse Phenome Database (table 1 in the online data supplement) [15]. $H 2-A a$ and $H 2-A b 1$ genes are haplotype $H 2^{k}$ in the $2 \mathrm{R}$ and $4 \mathrm{R}$ congenic strains, thus excluding these as candidate genes [13]. Additionally, the $\mathrm{H2}$ Eb1 gene is divided between resistant and susceptible haplotypes and therefore remains a candidate gene, as well as H2-Eb2 [16]. The genes that contain known non-synonymous polymorphisms between the B6 (susceptible) and C3 (resistant) mice in the reduced Inf2 in order of location on chromosome 17 are H2-Eb1, H2-Eb2, Btnl1, Notch4, Fkbpl, Crebl1, Tnxb, C4b, C4a and Stk19. Two genes (Hspa1b and Hspa1a) may have exonic polymorphisms between the B6 and C3, but no details are currently available for the B6 strain at these sites. Genes with intronic polymorphisms between the B6 (susceptible) and $\mathrm{C} 3$ (resistant) mice in the reduced Inf2 are: H2-Eb1, H2-Eb2, H2-Ea, Btln2, Btln1, Btln7, Notch4, Ppt2, Crebl1, Tnxb, C4b, Cyp21a1, C4a, Stk19, Cfb, C2, Msh5, Ddah2, Ly6g6c, Bat5, Ly6g5c, Csnk2b, Aif1, Tnf and Lta (table 1 in the online data 

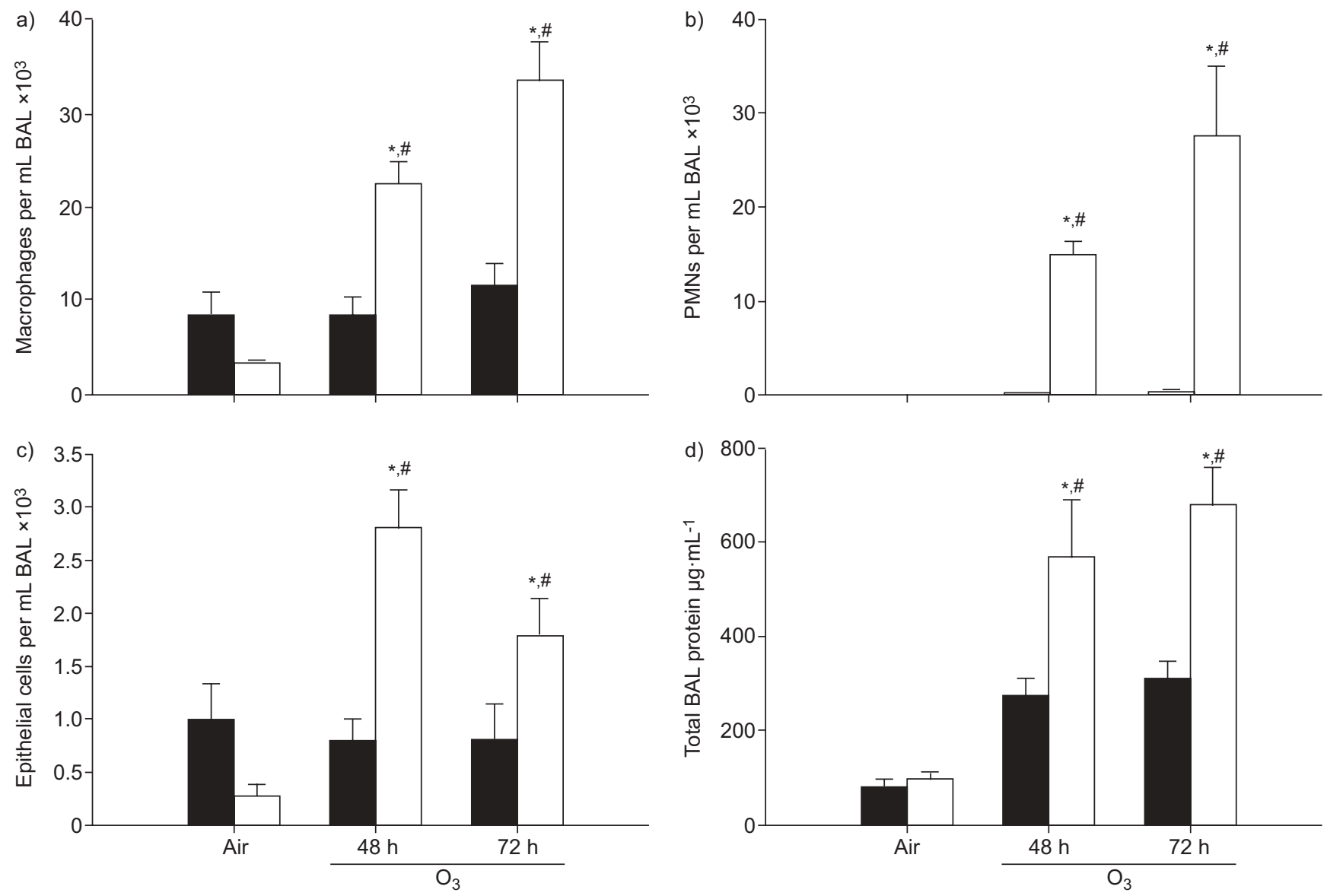

FIGURE 2. Bronchoalveolar lavage (BAL) fluid inflammatory parameters in the $\mathrm{C} 3 \mathrm{H}-\mathrm{H} 2^{\mathrm{b}}(\square)$ and $\mathrm{HeSnJ}(\boldsymbol{\square})$ mice exposed continuously to air or to 0.3 ppm $\mathrm{O}_{3}$ for 48 or 72 h. a) Macrophages, b) polymorphonuclear leukocytes (PMNs), c) epithelial cells and d) total BAL fluid protein. Data are presented as mean \pm SEM ( $n=3-5$ per experimental group). *: significantly different from air-exposed mice $(p<0.05)$; ${ }^{*}$ : significantly different from HeSnJ mice $(p<0.05)$.

supplement). UTR polymorphisms between the B6 and C3 mice were found in H2-Eb2, Btnl2, Ppt2, C4b,C4a, G6b, Bat5, Ly6g5b, and Tnf (table 1 in the online data supplement). Information is absent for $L t b$ and Tnf UTR and intronic polymorphisms in the C3 strain, thus it is possible that more exist between the B6 and $\mathrm{C} 3$ strains.

We then asked if mRNA expression differences between B6 and C3 mice existed for several candidate genes within the reduced Inf2, and with either known or possible single nucleotide polymorphisms (fig. 4). H2-Eb1 expression was reduced after $24 \mathrm{~h}$ of $\mathrm{O}_{3}$ exposure in the $\mathrm{C} 3$ mice, but unchanged in the B6 mice; $\mathrm{H} 2-\mathrm{Eb} 2$ expression was significantly increased only in B6 mice at $24 \mathrm{~h}$. Expression of Hspa1b and Btnl1 was significantly increased after $72 \mathrm{~h} \mathrm{O}_{3}$ in $\mathrm{B} 6$ mice only. Tnf and Lta expression was significantly increased in B6 mice after $24 \mathrm{~h} \mathrm{O}_{3}$ compared with no increases observed in C3 mice.

\section{MHC class // deficient mice}

Because of the prevalence of MHC class II genes in Inf2 and the non-synonymous, intronic and UTR polymorphisms in $H 2-E b 1$ and $-E b 2$ between the susceptible (B6) and resistant strains (C3) (table 1 in the online supplementary material), we hypothesised that they were candidate susceptibility genes for
$\mathrm{O}_{3}$-induced inflammation. $\mathrm{H} 2 \mathrm{Abl}^{-\mathrm{Ea}^{-/-}}$mice are deficient in MHC class II genes $H 2-A b 1,-A a,-E b 1,-E b 2$ and -Ea compared to the $\mathrm{H} 2 \mathrm{Abl}-\mathrm{Ea}^{+/+}$mice. The $\mathrm{B} 6$ background of these mice is null at $\mathrm{H} 2-\mathrm{Ea}$, therefore $\mathrm{H} 2 \mathrm{Abl}-\mathrm{Ea}^{-9-}$ mice only test the importance of the $H 2-A b 1$ through $H 2-E b 2$ MHC class II region. Relative to respective air controls, $\mathrm{O}_{3}$ caused significant $(\mathrm{p}<0.05)$ increases in mean numbers of BALF PMNs and macrophages in $\mathrm{H} 2 \mathrm{Abl}-\mathrm{Ea}^{+/+}$mice after 24,48 and $72 \mathrm{~h}$, and after 24 and $48 \mathrm{~h} \mathrm{O}_{3}$ in $\mathrm{H} 2 \mathrm{Abl}^{-\mathrm{Ea}^{-/-}}$mice (fig. $5 \mathrm{a}$ and $\mathrm{b}$, and table 2). However, significantly greater numbers of PMNs and macrophages were found in $\mathrm{H} 2 \mathrm{Abl}-\mathrm{Ea}^{+/+}$mice compared with $\mathrm{H} 2 \mathrm{Abl}-\mathrm{Ea}^{-/-}$mice after $24-72 \mathrm{~h}$ and 48 and $72 \mathrm{~h}$ exposures, respectively. Significant strain and $\mathrm{O}_{3}$ effects on BAL epithelial cells were found after $48 \mathrm{~h} \mathrm{O} \mathrm{O}_{3}$ (table 2). Significant strain differences in BAL protein content were also found after $48 \mathrm{~h} \mathrm{O}_{3}$ (fig. 5a). mRNA expression of Tnf and $\mathrm{Lta}$ was significantly increased in the $\mathrm{H} 2 \mathrm{Abl}-\mathrm{Ea}^{+/+}$mice after $24 \mathrm{~h} \mathrm{O}_{3}$; however, no increase was observed in the $\mathrm{H} 2 \mathrm{Abl}-\mathrm{Ea}^{-1-}$ mice (fig. $5 c$ and $d$ ).

\section{Mice deficient in Lta or the Tnf cluster}

Based on the existing evidence to support a role for the Tnf cluster in the $\mathrm{O}_{3}$ response [10], as well as the known intronic and UTR polymorphisms in Tnf and Lta genes between the B6 

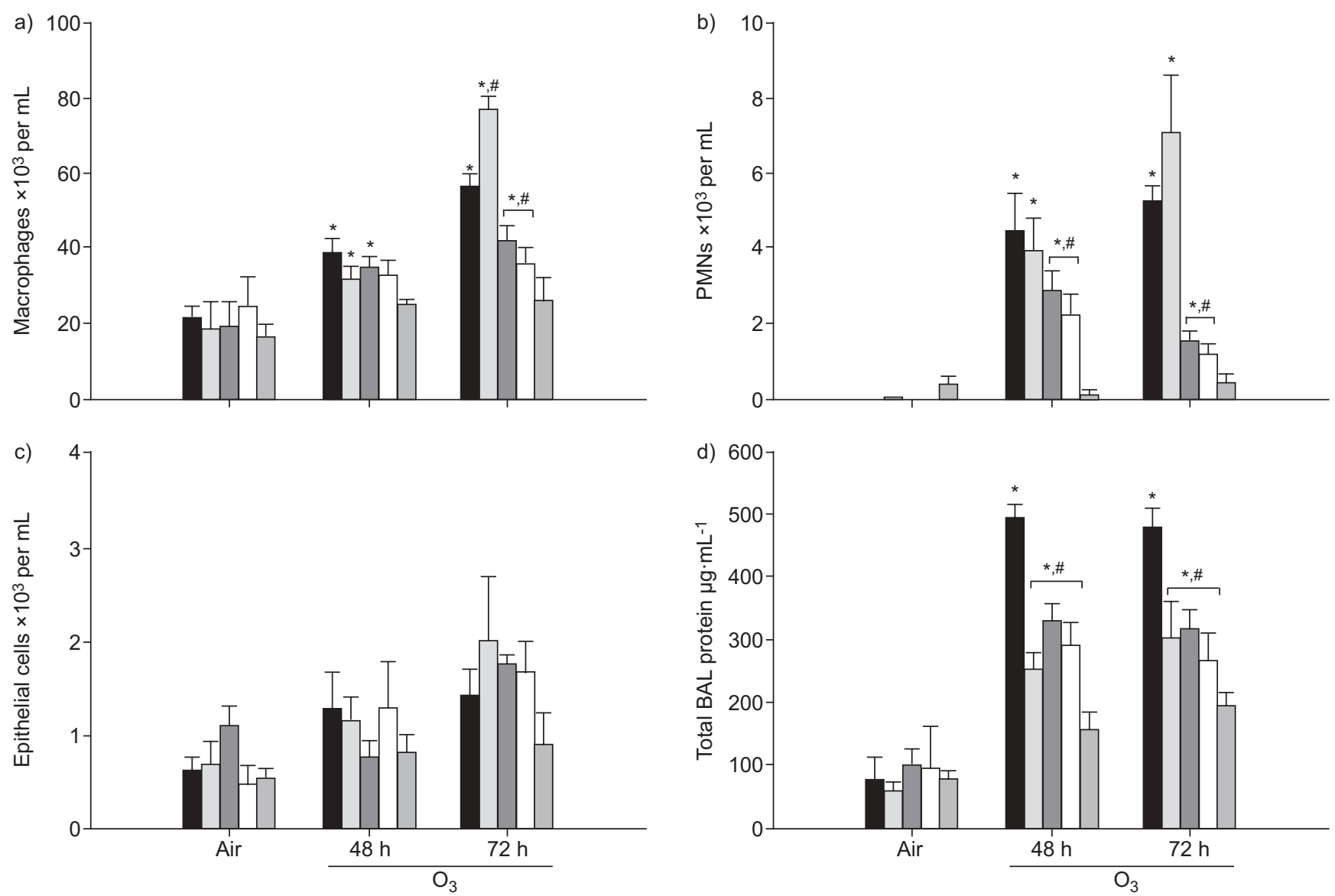

FIGURE 3. Bronchoalveolar lavage (BAL) fluid inflammatory parameters in $B 10$

4R ( $\square), 5 R(\square), 2 R(\square)$ and AWy $(\square)$ mice exposed continuously to air or to $0.3 \mathrm{ppm} \mathrm{O}_{3}$ for 48 or $72 \mathrm{~h}$. a) Macrophages, b) polymorphonuclear leukocytes (PMNs), c) epithelial cells and d) total BAL fluid protein. Data are presented as mean \pm SEM ( $n=3-12$ per experimental group). *: significantly different from air-exposed mice $(p<0.05)$; *: significantly different from $B 10$ mice $(p<0.05)$.

and HeJ mice, we tested the role of the Tnf cluster in the model. $\mathrm{Lta}^{-/-}, \mathrm{Lta} / \mathrm{Tnf} / \mathrm{Ltb}^{-/-}$, and wild-type mice were exposed continuously to air or 0.3 ppm $\mathrm{O}_{3}$ for 24,48 or $72 \mathrm{~h}$. PMNs were significantly elevated in the $\mathrm{Lta}^{+/+}$and $\mathrm{Lta} / \mathrm{Tnf} / \mathrm{Lt} \mathrm{b}^{+/+}$mice compared with mice deficient in Lta or the Lta/Tnf/Ltb cluster following 24 and $48 \mathrm{~h} \mathrm{O}_{3}$ for both strains, and $72 \mathrm{~h}$ exposure for $\mathrm{Lta} / \mathrm{Tnf} / \mathrm{Ltb}^{-/-}$mice compared with air controls ( $\mathrm{p}<0.05$; fig. 6ad). Mean numbers of BALF macrophages were also significantly elevated in wild-type mice compared with $\mathrm{Lta}^{-/-}$and Lta/Tnf/ $\mathrm{Ltb}^{-/-}$mice following 24-72 $\mathrm{h} \mathrm{O}_{3}$ compared with air controls $(\mathrm{p}<0.05$; table 2). Epithelial cell numbers were not different between exposure or strains (table 2). The BAL protein content was not affected by these genes, except for $72 \mathrm{~h}$ exposure in the $\mathrm{Lta}^{-/-}$mice, supporting the hypothesis that different genes regulate these specific phenotypes (fig. 6a-d) [17].

MHC class II gene expression was also significantly different between the strains deficient in the Tnf cluster. H2-Eb1 mRNA was unchanged in B6 wild-type mice; however, this gene was significantly decreased after $48 \mathrm{~h} \mathrm{O}_{3}$ in the $\mathrm{Lta}^{-/-}$and Lta/Tnf/ $\mathrm{Ltb}^{-/-}$mice compared with controls (fig. 6e and f). H2-Eb2 mRNA was significantly increased in B6 mice after 24 and $48 \mathrm{~h}$ $\mathrm{O}_{3}$, and was significantly greater after $\mathrm{O}_{3}$ than mRNA expression in $L t a^{-/-}$and $L t a / T n f / L t b^{-/-}$mice at these time points.

\section{DISCUSSION}

The overall objective of this investigation was two-fold. We first sought to restrict the length of Inf2 to elucidate candidate susceptibility genes for $\mathrm{O}_{3}$-induced inflammation. The second objective was to validate the role(s) of identified gene candidates. Significant differences in $\mathrm{O}_{3}$-induced inflammation between $\mathrm{C} 3 . \mathrm{SW}-\mathrm{H} 2 \mathrm{~b} / \mathrm{SJ}$ and $\mathrm{C} 3 \mathrm{H} / \mathrm{HeSnJ}$ strains confirmed the role of Inf2 inasmuch as the only difference between these two strains is a congenic region of chromosome 17 that encompasses Inf2. Comparison of inflammatory responses in $2 \mathrm{R}, 4 \mathrm{R}$ and $5 \mathrm{R}$ congenic mice with respective background strains further confirmed the importance of Inf2, and more importantly reduced Inf2 to $0.96 \mathrm{Mbp}$. The reduced Inf2 includes MHC class I, II, and III genes, and non-MHC genes, some of which have previously been identified as candidate genes in other lung injury models (e.g. C4a [18]). In the current study, gene expression and sequence analyses of the reduced Inf2 suggested that MHC class II genes and the Tnf cluster may be important in $\mathrm{O}_{3}$-induced inflammation, and significantly different phenotypes between $\mathrm{O}_{3}$-exposed $\mathrm{H} 2 \mathrm{Abl}-\mathrm{Ea}^{+/+}$and $\mathrm{H} 2 \mathrm{Abl}-\mathrm{Ea}^{-/-}$mice and the mice deficient in Lta alone or the entire Tnf cluster confirmed a role for these genes. To our knowledge, these are the first studies to conclusively demonstrate a role for MHC class II genes and the entire Tnf cluster in 

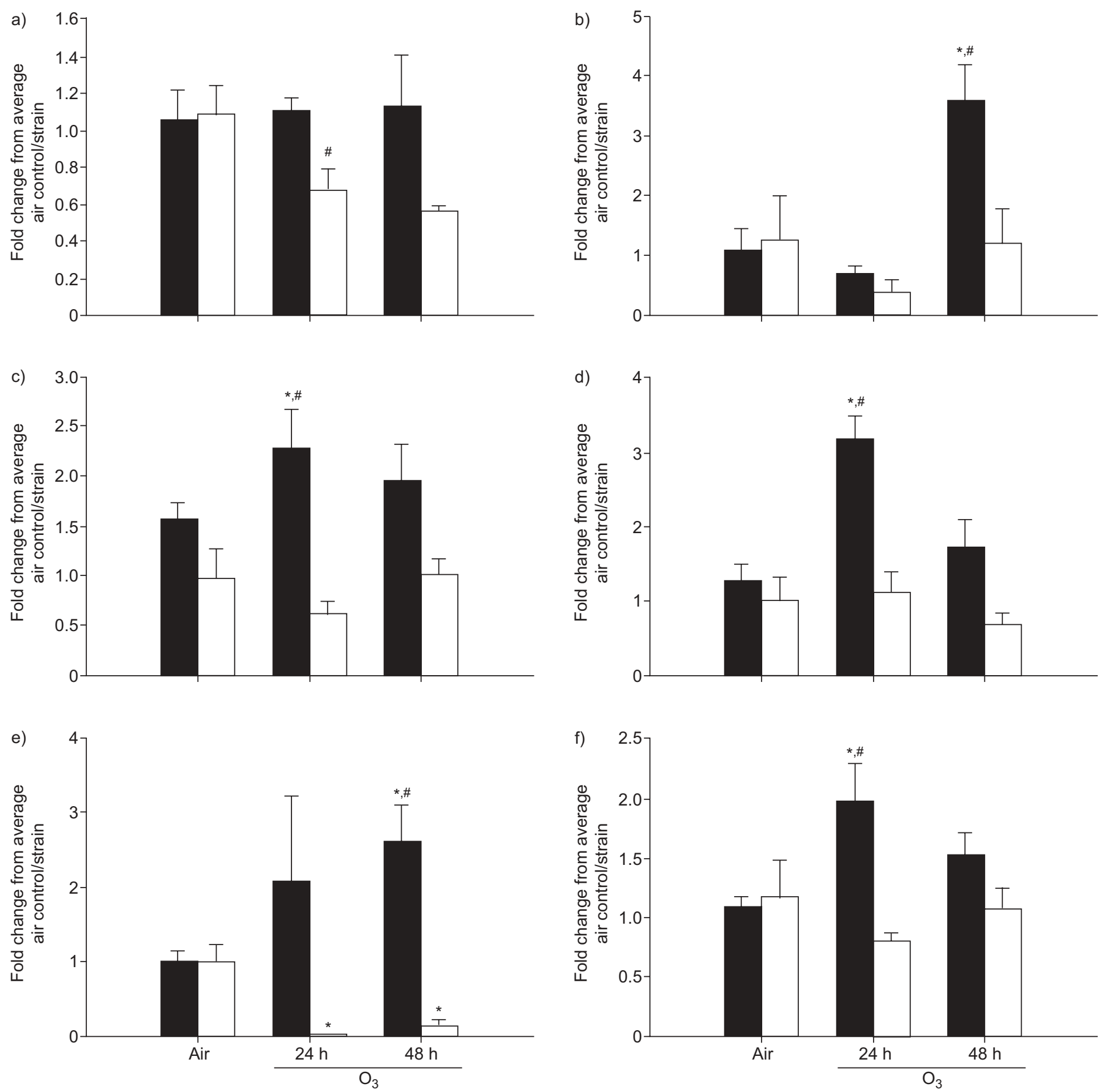

FIGURE 4. Gene expression for candidate genes identified within the reduced Inf2 region of B6 (susceptible; $\square$ ) and C3 (HeJ, resistant; $\square$ ) mice. Six genes were analysed using quantitative RT-PCR: a) H2Eb1, b) Btn/1, c) H2Eb2, d) Tnf, e) Hspa1b and f) Lta. Data are presented as mean \pm SEM ( $\mathrm{n}=3-7$ per experimental group) and were determined using the comparative $\mathrm{C}_{\mathrm{T}}$ method (Materials and methods section of the online supplementary material). The $y$-axis represents the gene of interest normalised first to $18 \mathrm{~S}$ followed by determination of the fold-change relative to the average air control value for each strain. *: significantly different from air-exposed mice $(\mathrm{p}<0.05)$; \#: significantly different from B6 mice $(p<0.05)$.

oxidant-induced lung inflammation and provide evidence supporting a susceptibility "superlocus".

Genetic association studies have implicated several gene categories, such as pro-inflammatory cytokine genes [9], metabolism genes [19] and innate immunity genes, in responses to environmental stimuli in human populations [20].
In inbred mouse models, positional cloning approaches identified QTLs for a number of lung diseases [21]. However, while identification of QTLs is an important initial step in understanding the genetic determinants of disease, QTLs can contain hundreds of genes. It is, therefore, necessary to refine the disease QTLs to a limited set of genes that can be evaluated [22]. In our integrative genomics approach to reducing Inf2 and 

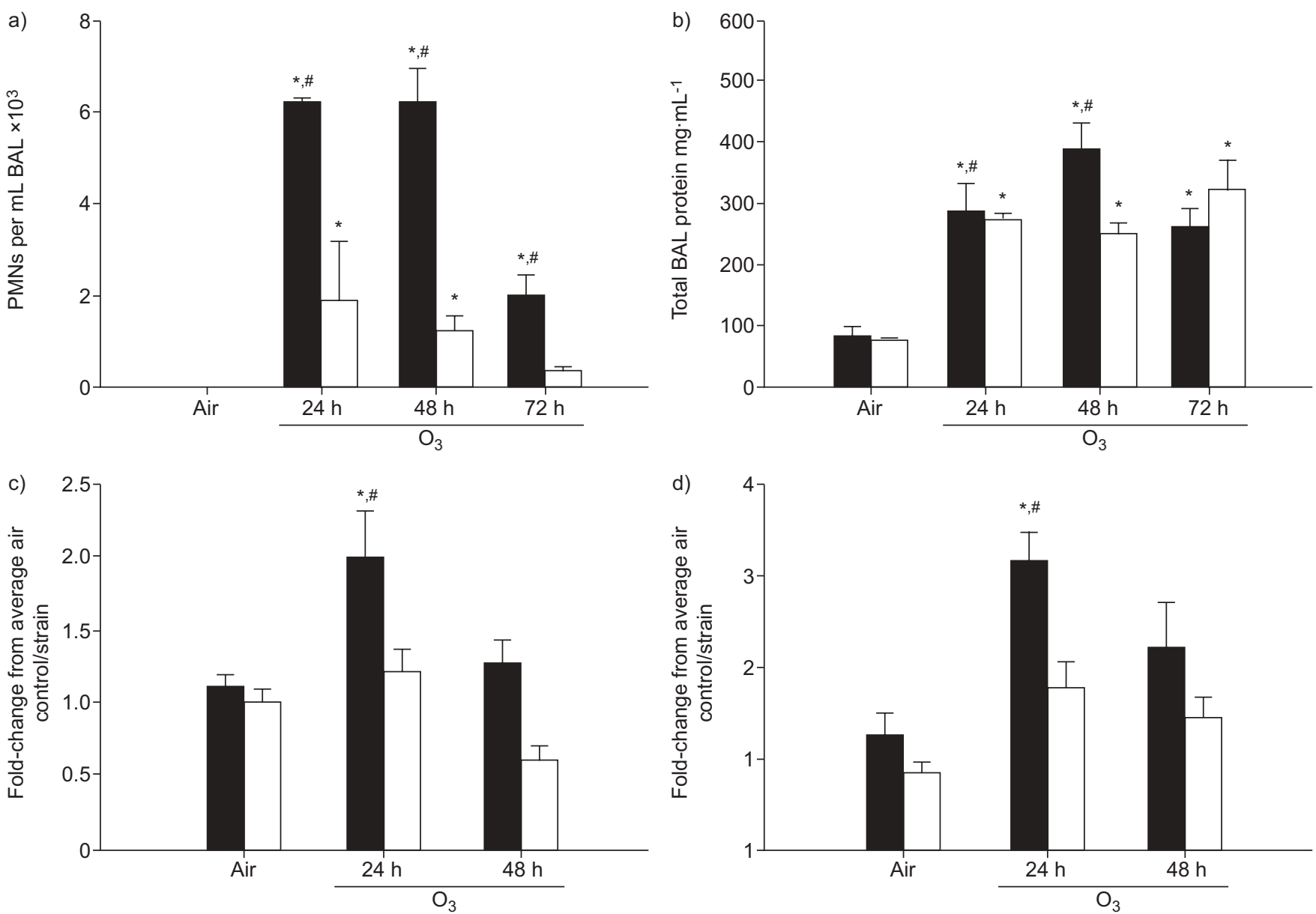

FIGURE 5. Deficiency in major histocompatibility complex class $\|$ genes significantly reduced $\mathrm{O}_{3}$-induced responses. a) Bronchoalveolar lavage (BAL) fluid polymorphonuclear leukocytes (PMNs) and b) total protein in $\mathrm{H}_{2} \mathrm{Ab} 1-\mathrm{Ea}^{-1-}(\square)$ and $\mathrm{H} 2 \mathrm{Ab} 1-\mathrm{Ea}^{+/+}$( $\left.\mathbf{\square}\right)$ mice exposed continuously to air or to 0.3 ppm $\mathrm{O}_{3}$ for 24,48 or $72 \mathrm{~h}$. Data are presented as mean \pm SEM ( $n=3-10$ per experimental group). Gene expression for c) Lta and d) Tnf genes in H2Ab1-Ea deficient mice ( $\square$ ) compared with wild-type mice

(匹). Data are presented as mean \pm SEM $\left(n=3-6\right.$ per experimental group) and were determined using the comparative $C_{T}$ method (Materials and methods section of the online supplementary material). The $y$-axis represents either Lta or Tnf normalised first to $18 \mathrm{~S}$ followed by determination of the fold-change relative to the average air control value for each strain. *: significantly different from air-exposed mice $(p<0.05)$; ${ }^{*}$ : significantly different from H2Ab1-Ea ${ }^{+/+}$mice $(p<0.05)$.

identifying candidate genes, we used congenic strains that were developed initially for histo-incompatibility studies by repeated backcrossing of regions of chromosome 17 from the donor strain onto the recipient background strain [23]. One advantage of these strains is that the allelic designations are well characterised and, after phenotyping these strains for their inflammatory response to $\mathrm{O}_{3}$, it enabled restriction of the previously described Inf2 QTL to a limited chromosomal interval to identify gene candidates.

We queried the Mouse Phenome Database to identify genes located within the narrowed Inf2 that are polymorphic between susceptible B6 and resistant C3 mice. Several of the MHC class II and III genes (and those non-MHC genes located within these regions) have non-synonymous polymorphisms in exons, many have intronic polymorphisms, and several have UTR polymorphisms. However, not all of the genes have been assessed for polymorphisms between B6 and C3 mice (e.g. Hspa $1 b$ ). It is important to note that functional polymorphisms may also exist in intronic regions, such as with $K$-ras and mouse lung cancer [24]. Future studies will delineate the functionality of polymorphic regions between the B6 and $\mathrm{C} 3$ mice in those genes in which the functionality is unknown, such as $L t b$.

\section{Organisation of the $\mathrm{H} 2$ locus}

Genes in the mouse $H 2$ locus and the homologous human MHC locus are organised in the same relative gene order [25] and span several Mbp. The $H 2$ locus contains class I, class II and class III genes. Class I and class II genes are important in fulfilling immunological functions. Class I molecules are expressed by most cells, and present endogenous antigens (cytosolic-derived) to CD8+ cytotoxic T-cells. Class II molecules (e.g. H2-Eb2, Btnl1) are expressed in antigen presenting cells, such as dendritic cells, and present exogenous, endocytically derived antigens to CD4+ helper T-cells [26]. Class III genes are diverse in functionality, are located between the class I and class II genes and include the complement component genes (C2 and C4), heat shock proteins (Hspa1a, Hspa1b, and $\mathrm{Hsc} 70 \mathrm{t})$ and the Tnf cluster. 

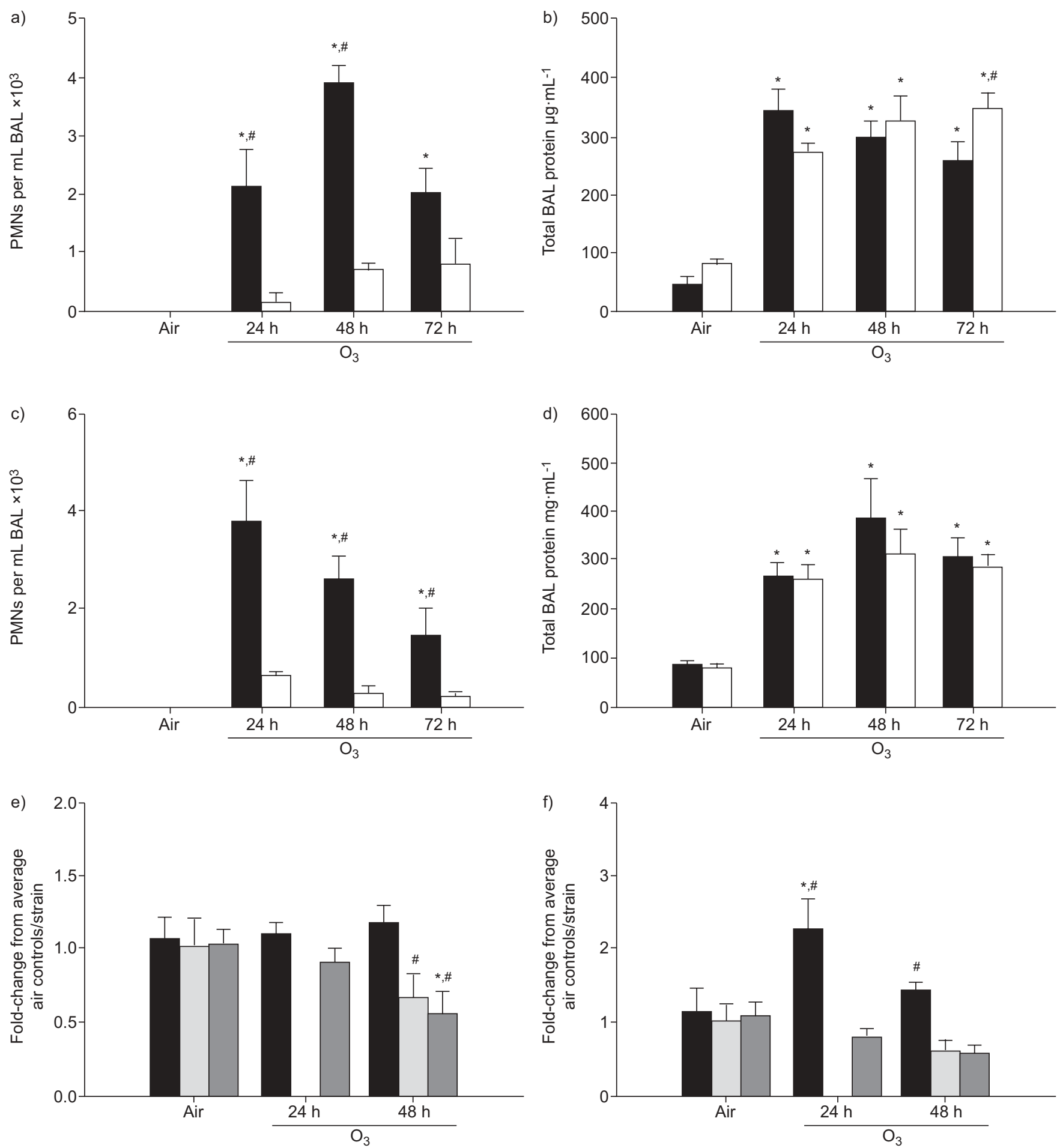

FIGURE 6. $\mathrm{O}_{3}$-induced responses in mice deficient in Lta or the Tnf cluster (Lta, Tnf, Ltb) genes. Bronchoalveolar lavage (BAL) fluid a) polymorphonuclear leukocytes (PMNs) and b) total protein for mice deficient in $L$ ta $(\square)$ and their wild-type controls $(\mathbf{\square})$. Data are presented as mean \pm SEM $(n=3-10$ per experimental group). *: significantly different from air-exposed mice $(p<0.05)$; ${ }^{*}$ : significantly different from $L t{ }^{+/+}$mice $(p<0.05)$. c and d) BAL fluid inflammatory parameters for the $L$ ta/Tnf $/ L t b$ deficient mice $(\mathbf{\square})$ in response to $\mathrm{O}_{3}$ compared to wild-type mice $(\square)$. Data are presented as mean \pm SEM ( $n=3-10$ per experimental group). *: significantly different from air-exposed mice $(p<0.05) ;{ }^{\#}$ : significantly different from Lta/Tnf/Ltb ${ }^{+/+}$mice $(p<0.05)$. Gene expression for the major histocompatibility complex class II genes e) H2-Eb1 and f) H2-Eb2 in the mice deficient in either $L t a(\square)$ or $L$ ta/Tnf/Ltb $(\square)$ compared with the wild-type mice $(\mathbf{\square})$. B6 are the wild type for both strains and the numbers were combined since they were not significantly different from one another. No $24 \mathrm{~h}$ samples for $\mathrm{Lta} / \mathrm{Tnf} / \mathrm{Lt} \mathrm{b}^{-/-}$mice were done for gene expression analysis. Data are presented as means $\pm \mathrm{SEM}(\mathrm{n}=3-6 \mathrm{per}$ experimental group) and were determined using the comparative $\mathrm{C}_{T}$ method (Materials and methods section of the online supplementary material). The $y$-axis represents either $\mathrm{H} 2$-Eb1 or $\mathrm{H} 2$-Eb2 normalised first to $18 \mathrm{~S}$ followed by determination of the fold-change relative to the average air control value for each strain. *: significantly different from air-exposed mice $(p<0.05)$; ${ }^{*}$ : significantly different from wild-type mice $(p<0.05)$. 


\begin{tabular}{|c|c|c|c|c|c|}
\hline TABLE 2 & $\begin{array}{l}\text { H2-Abl-Ea, } \mathrm{L} \\
\mathrm{g} \mathrm{O}_{3} \text { expos }\end{array}$ & hf/Ltb on & ges and ep & ells recover & onchoalveolar \\
\hline \multirow[t]{2}{*}{ Cell type } & \multirow[t]{2}{*}{ Genotype } & \multirow[t]{2}{*}{ Air $^{\#}$} & \multicolumn{3}{|c|}{$\mathrm{O}_{3}$ exposed } \\
\hline & & & $24 \mathrm{~h}$ & $48 \mathrm{~h}$ & $72 \mathrm{~h}$ \\
\hline \multirow[t]{4}{*}{ Macrophages } & $\mathrm{H} 2 \mathrm{Abl}-\mathrm{Ea}^{+/+}$ & $19.6 \pm 0.1$ & $33.6 \pm 3.9^{*}$ & $48.1 \pm 0.4^{\star \bullet}$ & $37.9 \pm 3.7^{\star}$ \\
\hline & $\mathrm{Lta}^{-/-}$ & $13.8 \pm 1.9$ & $7.6 \pm 2.2$ & $21.2 \pm 2.7$ & $32.0 \pm 2.5^{\star}$ \\
\hline & $L t a / T n f / L t b^{+/+}$ & $18.3 \pm 3.4$ & $26.7 \pm 3.0$ & $36.8 \pm 3.9^{*}$ & $38.5 \pm 3.4^{*, 9}$ \\
\hline & $L t a / T n f / L t b^{-/-}$ & $26.6 \pm 3.2$ & $32.7 \pm 3.7$ & $25.2 \pm 3.0$ & $24.4 \pm 3.9$ \\
\hline \multirow[t]{2}{*}{ Epithelial cells } & $\mathrm{MHC}^{+/+}$ & $1.4 \pm 0.3$ & $1.0 \pm 0.2$ & $2.6 \pm 0.7^{\star} \cdot$ & $1.0 \pm 0.3$ \\
\hline & $\mathrm{MHC}^{-/-}$ & $0.1 \pm 0.2$ & $1.8 \pm 0.6$ & $0.9 \pm 0.1$ & $0.9 \pm 0.2$ \\
\hline
\end{tabular}

\section{Candidate gene analysis}

Deficiency in MHC class II genes and the Tnf cluster decreased the $\mathrm{O}_{3}$-induced $\mathrm{PMN}$ and macrophage phenotypes, similar to those reductions seen in the $2 \mathrm{R}$ and $5 \mathrm{R}$ mice. Previous studies, as well as the data presented here, support a clear role for the Tnf cluster in these $\mathrm{O}_{3}$-induced phenotypes. The H2-Ea gene (which is deficient in B6 mice), H2-Ab1 and H2- $A a$ (as described earlier) can be excluded as candidate susceptibility genes.

CHEN et al. [27] demonstrated that inhibition of the CD4+ T-cell population using a monoclonal CD4 antibody in vivo greatly reduced the $\mathrm{O}_{3}$-induced phenotypes (including PMNs, lymphocytes and epithelial cells) in B6 mice after $72 \mathrm{~h}$ continuous $\mathrm{O}_{3}$ exposure. These studies support our findings in the $\mathrm{H} 2 \mathrm{Abl}-$ $\mathrm{Ea}^{-/-}$mice and suggest that, in $\mathrm{O}_{3}$ susceptible strains, CD4+ Tcells are critical to $\mathrm{O}_{3}$-induced inflammation and injury. A recent study in human airway monocytes isolated from exposed individuals suggests that $\mathrm{O}_{3}$ primes the airway monocytes for innate immune responses, increases the capacity of the monocytes to present antigen to the CD4+ T-cells and increases the overall population of antigen presenting cells in the lungs [20].

\section{Candidate susceptibility genes in Inf2 and human disease}

The MHC class II genes and the Tnf cluster in the reduced Inf2 are all located in close proximity on chromosome 17 in mice and chromosome 6 in humans (fig. 1 ; table 1 of the online supplementary material). Several of these homologous genes have been implicated in human association studies. For example, polymorphisms in HLA-DRB1 (H2-Eb1), TNF and LTA have been associated with sarcoidosis [28], a chronic granulomatous disease of unknown aetiology, supporting a role for a susceptibility "superlocus". In addition, TNF is a susceptibility gene for $\mathrm{O}_{3}$-induced changes in lung function in humans [29]. Thus, it is possible that a cluster of genes in the
MHC class II region (H2-Eb1 and H2-Eb2) interacts with the Tnf cluster ( $T n f$, Lta and $L t b$ ) to promote $\mathrm{O}_{3}$-induced lung inflammation and injury. In support of this notion, the MHC (specifically HLA genes) has the strongest influence on susceptibility to human autoimmune diseases, but recent evidence suggests that TNF may also be involved in autoimmune diseases [30].

In summary, this integrative genomics investigation utilised congenic mouse lines to narrow the chromosome 17 QTL for susceptibility to $\mathrm{O}_{3}$-induced inflammation in the mouse. We used sequence analysis to identify candidate genes in the narrowed QTL, which were then tested for proof of concept. The novel role of MHC Class II genes and the Tnf cluster in susceptibility to $\mathrm{O}_{3^{-}}$ induced inflammation provides unique insight to the mechanisms of $\mathrm{O}_{3}$ effects in the lung and may lead to alternative means to prevent oxidant injury to lung tissues.

\section{SUPPORT STATEMENT}

This research was supported by the Intramural Research program of the National Institute of Environmental Health Sciences, National Institutes of Health, Dept of Health and Human Services (S.R. Kleeberger, H-Y. Cho, C. Walker, S. Tivedi, W. Gladwell) and Michigan State University (A.K. Bauer and E.A. Rondini).

\section{STATEMENT OF INTEREST}

A statement of interest for this study can be found at www.erj. ersjournals.com $/ \mathrm{misc} /$ statements.dtl

\section{ACKNOWLEDGEMENTS}

Ozone exposures were conducted at the National Institute of Environmental Health Sciences Inhalation Facility under contract to Alion Science and Technology, Inc. (Research Triangle Park, NC, USA). The authors thank D. Morgan and H. Price at Alion Science and Technology, Inc. for coordinating the inhalation exposures. We also thank D. Cook (NIEHS, Research Triangle Park, NC, USA) for reviewing the manuscript and providing excellent suggestions. 


\section{REFERENCES}

1 Delfino RJ, Murphy-Moulton AM, Burnett RT, et al. Effects of air pollution on emergency room visits for respiratory illnesses in Montreal, Quebec. Am J Respir Critical Care Med 1997; 155: 568-576.

2 Romieu I, Sienra-Monge JJ, Ramírez-Aguilar M, et al. Genetic polymorphism of GSTM1 and antioxidant supplementation influence lung function in relation to ozone exposure in asthmatic children in Mexico City. Thorax 2004; 59: 8-10.

3 US EPA. Air Quality Criteria for Ozone and Related Photochemical Oxidants (2006 Final). Washington, US Environmental Protection Agency, 2006. EPA/600/R-05/004aF-cF.

4 Goldstein BD, Lai LY, Ross SR, et al. Susceptibility of inbred mouse strains to ozone. Arch Environ Health 1973; 27: 412-413.

5 Kleeberger SR, Levitt RC, Zhang LY, et al. Linkage analysis of susceptibility to ozone-induced lung inflammation in inbred mice. Nat Genet 1997; 17: 475-478.

6 Prows DR, Shertzer HG, Daly MJ, et al. Genetic analysis of ozoneinduced acute lung injury in sensitive and resistant strains of mice. Nat Genet 1997; 17: 471-474.

7 Alexis NE, Zhou H, Lay JC, et al. The glutathione-S-transferase Mu 1 null genotype modulates ozone-induced airway inflammation in human subjects. J Allergy Clin Immunol 2009; 124: 1222-1228.

8 Bergamaschi E, De Palma G, Mozzoni P, et al. Polymorphism of quinone-metabolizing enzymes and susceptibility to ozone-induced acute effects. Am J Respir Crit Care Med 2001; 163: 1426-1431.

9 Lee $\mathrm{YL}$, McConnell R, Berhane K, et al. Ambient ozone modifies the effect of tumor necrosis factor G-308A on bronchitic symptoms among children with asthma. Allergy 2009; 64: 1342-1348.

10 Cho HY, Zhang LY, Kleeberger SR. Ozone-induced lung inflammation and hyperreactivity are mediated via tumor necrosis factor-alpha receptors. Am J Physiol Lung Cell Mol Physiol 2001; 280: L537-L546.

11 Stewart CA, Horton R, Allcock RJ, et al. Complete MHC haplotype sequencing for common disease gene mapping. Genome Res 2004; 14: $1176-1187$.

12 Mouse Genome Informatics. www.informatics.jax.org/javawi2/ wifetch?page $=$ markerQF Date last accessed: July 21, 2009. Date last updated: May 19, 2010.

13 Laboratories J. H2 Haplotype Appendix 2. http://jaxmice.jax.org/ literature/catalog/mhc_h2_haplotypes.pdf Date last accessed: March 2, 2009.

14 Bauer AK, Dixon D, DeGraff LM, et al. Toll-like receptor 4 in butylated hydroxytoluene-induced mouse pulmonary inflammation and tumorigenesis. J Nat Cancer Inst 2005; 97: 1778-1781.

15 Laboratory MPPatJ. Mouse Phenome Database. www.phenome. jax.org/SNP Date last accessed: July 1, 2009. Updated 2010.
16 Hood L, Steinmetz M, Malissen B. Genes of the major histocompatibility complex of the mouse. Annu Rev Immunol 1983; 1: 529-568.

17 Kleeberger SR, Reddy S, Zhang LY, et al. Genetic susceptibility to ozone-induced lung hyperpermeability: role of toll-like receptor 4 . Am J Respir Cell Mol Biol 2000; 22: 620-627.

18 Haston CK, Tomko TG, Godin N, et al. Murine candidate bleomycin induced pulmonary fibrosis susceptibility genes identified by gene expression and sequence analysis of linkage regions. J Med Genet 2005; 42: 464-473.

19 Islam T, Berhane K, McConnell R, et al. Glutathione-S-transferase (GST) P1, GSTM1, exercise, ozone and asthma incidence in school children. Thorax 2009; 64: 197-202.

20 Lay JC, Alexis NE, Kleeberger SR, et al. Ozone enhances markers of innate immunity and antigen presentation on airway monocytes in healthy individuals. J Allergy Clin Immunol 2007; 120: 719-722.

21 Bauer AK, Malkinson AM, Kleeberger SR. Susceptibility to neoplastic and non-neoplastic pulmonary diseases in mice: genetic similarities. Am I Physiol Lung Cell Mol Physiol 2004; 287: L685L703.

22 Kleeberger SR, Schwartz DA. From quantitative trait locus to gene: a work in progress. Am J Respir Crit Care Med 2005; 171: 804-805.

23 Silver L. Mouse Genetics. Concepts and Applications. New York, Oxford University Press, 1995

24 Chen B, Johanson L, Wiest JS, et al. The second intron of the K-ras gene contains regulatory elements associated with mouse lung tumor susceptibility. Proc Natl Acad Sci USA 1994; 91: 1589-1593.

25 Snoek M, Groot PC, Spies T, et al. Fine mapping of the crossoversites in the $\mathrm{C} 4-\mathrm{H}-2 \mathrm{D}$ region of $\mathrm{H}-2$ recombinant mouse strains. Immunogenetics 1991; 34: 409-412.

26 Snoek M, Teuscher C, van Vugt H. Molecular analysis of the major MHC recombinational hot spot located within the G7c gene of the murine class III region that is involved in disease susceptibility. J Immunol 1998; 160: 266-272.

27 Chen X, Gavett SH, Wills-Karp M. CD4+ T lymphocyte modulation of ozone-induced murine pulmonary inflammation. Am J Respir Cell Mol Biol 1995; 12: 396-403.

28 Mrazek F, Holla LI, Hutyrova B, et al. Association of tumour necrosis factor-alpha, lymphotoxin-alpha and HLA-DRB1 gene polymorphisms with Lofgren's syndrome in Czech patients with sarcoidosis. Tissue Antigens 2005; 65: 163-171.

29 Yang IA, Holz O, Jorres RA, et al. Association of tumor necrosis factor-alpha polymorphisms and ozone-induced change in lung function. Am J Respir Crit Care Med 2005; 171: 171-176.

30 Camarena A, Juarez A, Mejia M, et al. Major histocompatibility complex and tumor necrosis factor-alpha polymorphisms in pigeon breeder's disease. Am J Respir Crit Care Med 2001; 163: 1528-1533. 